\title{
Vicisitudes de la iglesia mozárabe de San Marcos de Toledo
}

\author{
Ángel Santos Vaquero ${ }^{1}$
}

\section{RESUMEN}

Aunque en el siglo XI el papado intentó unificar la liturgia en toda la cristiandad, en Toledo quedaron seis parroquias denominadas mozárabes, después de ser conquistada por los cristianos. Una de ellas es la de san Marcos, la cual sufrió durante su existencia una serie de sucesos (ruina, incendio, reparaciones, unificaciones y traslados). En este artículo señalamos, ante todo, la reparación efectuada a comienzos del siglo XVIII y tratamos de que no sea confundida con la iglesia de San Marcos, que fue de los Trinitarios, y en la que fue acomodada la citada parroquia.

\section{PALABRAS CLAVE}

Parroquia mozárabe, San Marcos, Toledo, reparación, siglo XVIII, trinitarios

\section{Events of the mozarabic church of San Marcos de Toledo}

ABSTRACT

Although in the eleventh century the papacy tried to unify the liturgy in all Christianity, in Toledo there remained six parishes called Mozarabs, after being conquered by the Christians. One of them is that of St Mark, who suffered during his existence a series of events (ruin, fire, repairs, unifications and transfers). In this article we mention, first of all, the repair carried out at the beginning of the eighteenth century and we try not to confuse it with the church of San Marcos, which was of the Trinitarians, and in which the said parish was accommodated.

\section{KEYWORDS}

Mozarabic parish, San Marcos, Toledo, repair, 18th century, trinitarians.

1 angelsantosvaquero@gmail.com ORCID: $0 \mathrm{rg} /$ 0000-0003-2369-2014 


\section{Introducción}

La parroquia mozárabe de San Marcos, es una de las seis que los árabes permitieron a los cristianos, después de conquistar Toledo: Santas Justa y Rufina, Santa Eulalia, San Sebastián, San Marcos, San Lucas y San Torcuato (nombradas por orden de erección), además de Santa María de Alficén ${ }^{1}$ y algunas otras ermitas. Este hecho se debió a las capitulaciones bajo las que fue entregada Toledo a los musulmanes ${ }^{2}$. Con ello aceptaron y toleraron que los cristianos que quedaron viviendo en la ciudad, pudieran continuar con su creencia y ritos, con alguna contraprestación, como la de pagar unos impuestos especiales.

Estas parroquias recibieron el nombre de "mozárabes" por cobijar a cristianos dentro de territorio musulmán, las cuales mantuvieron el rito apostólico transmitido por San Leandro y San Isidoro y continuado por San Ildefonso y San Julián, arzobispos de Toledo. Este rito fue continuado en Toledo y otras ciudades y pueblos de España hasta que el papa Gregorio VII se propuso unificar el rito eclesiástico en toda la cristiandad, ante el mantenimiento enmascarado de ciertos vestigios de la doctrina herética adopcionista de Félix de Urgell e impulsada por el metropolitano de Toledo, Elipando, en el siglo VIII, por lo que se mostró decidido a que se aboliese en España el denominado mozárabe -del que se decía "puro"- y se sustituyese por el romano, como ya se había hecho en otras naciones cristianas, entre las que se encontraba Francia. Aragón y Cataluña cedieron ante el papado, pero Navarra y Castilla se resistían a tal obediencia.

A Alfonso, que se consideró el Emperador de las "Dos Religiones" (cristiana e islámica), se le presentó después de la conquista de Toledo, además de un problema socio-político y otro económico, uno más añadido: el religioso dentro de la sociedad cristiana, teniendo en cuenta que en el año de 1080 (finales de abril o principios de mayo) se había celebrado un concilio en

Iglesia que se hallaba en la parte más baja de la zona oriental de la ciudad, cerca del puente de Alcántara.

Es de señalar el leal, noble y honesto comportamiento de los musulmanes, que cumplieron con su compromiso, mientras los cristianos, tras la reconquista de Toledo, se comportaron de manera totalmente deshonrosa e indigna, ya que no respetaron lo que habían firmado en las capitulaciones que aceptaron para apoderarse de la ciudad.
Burgos en el que se estableció el cambio del rito mozárabe al romano. La liturgia que se utilizaba en la Península, como decíamos, era distinta de la que se practicaba en el resto de las Iglesias europeas. En realidad sólo se diferenciaba del rito romano en lo accesorio, siendo prácticamente igual en lo sustancial; pero el papa Alejandro II (1061-1073), a pesar de que en 1066 fue reconocida por la Santa Sede la ortodoxia del rito hispánico, pretendió con insistencia que en la Hispania cristiana se abandonase el rito isidoriano y se acatase el romano, política que continuó con más fuerza Gregorio VII, porque consideraba esta liturgia contaminada por las teologías arriana y musulmana después de tanto tiempo de convivencia. Pero el propósito de este papa, envalentonado tras su triunfo sobre el emperador en la "guerra de las investiduras" y protegido por la consecución de los "Dictatus Papae", que le conferían la facultad de la infalibilidad en asuntos religiosos, además de unificar el rito eclesiástico, envolvía otro más práctico y mundano: arrancar la Iglesia de manos de los laicos, es decir, redefinir los fundamentos de la sociedad cristiana estipulando nuevas bases de las competencias laicas y eclesiásticas. Para ello necesitaba una reforma interna de la Iglesia, que tenía como pieza principal el reforzamiento de su jerarquización orgánica, encabezada por el Pontífice, con reducción de las diferencias canónicas nacionales

El arzobispo de Toledo, don Bernardo, de origen francés, apoyado por doña Constanza, esposa de Alfonso VI -asimismo de origen galo- presionó al monarca para obedecer al pontífice. Con la aquiescencia de Alfonso, el arzobispo de Toledo mandó congregar un concilio en la catedral, al que acudieron muchos obispos y clérigos y que contó con la presencia del rey y su corte. En este concilio se mandó que de ese momento en adelante se cumpliesen los mandatos del Papa y se usase el rito romano, cesando el mozárabe. Sin embargo, esta decisión chocó con la decidida oposición del pueblo y bajo clero, que se negaban a renegar de sus tradiciones religiosas, llegando a producirse graves altercados en Castilla por esta causa y en especial en Toledo. Es importante tener en cuenta que mozárabes relevantes ocupaban destacadas dignidades en el cabildo catedralicio, así como altos cargos en el gobierno de la ciudad. La oposición decidida de los mozárabes toledanos a perder la liturgia hispana, que suponía para ellos una tradición heredada que 
constituye un signo referente a su origen, consiguió que en Toledo se permitiese la existencia de seis parroquias mozárabes, donde se siguió practicando el rito y la misa transmitida por San Leandro. No obstante, a partir del siglo XIV fue decayendo la feligresía mozárabe $\mathrm{y}$, a pesar de que en el XVI todavía los adscritos a estas parroquias constituían un número considerable, la verdad es que su extinción fue total en algunas de ellas ${ }^{3}$. En Toledo se ha mantenido esta liturgia a lo largo de los siglos gracias a la labor desarrollada por prelados de la diócesis como Rodrigo Jiménez de Rada (s. XIII), Gonzalo García Gudiel (s. XIII, de origen mozárabe), Pedro González de Mendoza (s. XV) y Francisco Jiménez de Cisneros (s. XV-XVI).

Este último cardenal puso un gran empeño en recuperar el rito mozárabe en Toledo al fijar su atención en unos viejos códices de la Biblioteca Capitular, así como breviarios y misales referentes al mismo. Este descubrimiento avivó sus positivas emociones hacia esos sentimientos religiosos. Tras ello, tomó la decisión de imprimir la liturgia visigótica para su conservación y crear en la catedral primada una capilla para la celebración de esa liturgia, dotándola de suficiente renta para su mantenimiento y de sacerdotes para el culto. Es la llamada del Corpus Christi o Mozárabe, en la que, con autorización papal se continúa celebrando misa de rito mozárabe.

Como ya expusimos, una de estas parroquias mozárabes fue la de San Marcos, la cual se hallaba ubicada en el callejón al que dio nombre. Ateniéndonos a unos versos escritos por San Ildefonso, se deduce que esta iglesia se construyó en el 6344, "bajo el reinado de Sisenando, por una ilustre señora de la sangre real de los godos, llamada Blesila"5. En el siglo

\footnotetext{
En el siglo XIX se suprimieron cuatro, quedando Santas Justa y Rufina -a la que se adscribieron las de San Lucas y San Sebastián- y la de San Marcos -que asumió las de San Torcuato y Santa Eulalia-, PARRO, S.R., Toledo en la mano, t. II, Toledo, 1857, p.174. En la actualidad quedan sólo dos matrices: Santas Justa y Rufina, con filiales las de San Lucas y San Sebastián (aunque los templos de estas dos subsisten), y la de Santa Eulalia, que engloba como filiales a las de San Marcos y San Torcuato, cuyos templos desparecieron. Estas parroquias mozárabes no poseen territorio propio, sino que son personales, es decir, los mozárabes toledanos están adscritos a una parroquia determinada, vivan donde vivan, ya sea en la misma Toledo o en otra población, por razón de rito (Código de D.C. $n^{\circ}$ 518).

PARR0, S.R., Toledo en la..., pp.169-171

PARRO, S.R., Toledo en la..., p. 185
}

XVI fue reedificada y a comienzos de la década de 1700 la iglesia necesitaba una profunda reparación en su armadura, chapitel y paredes maestras. Con este artículo, pretendemos poner de relieve las incidencias que atravesó a lo largo de su existencia y, tras hallar en el Archivo Histórico Provincial de Toledo un documento en el protocolo $\mathrm{n}^{\circ} 491$, del escribano Gabriel Ruiz de Arrieta ${ }^{6}$, la situación en que se hallaba el templo a comienzos del siglo XVIII y la precisión de los reparos que eran precisos realizar en su fábrica. Por último, ponemos de relieve la diferenciación con la iglesia de San Marcos, de origen trinitario, en la que fue ubicada la parroquia mozárabe de San Marcos tras la ruina de su sede y después de varios traslados.

\section{Manifestación de las necesidades de reparación}

A principios del siglo XVIII necesitaba la iglesia de la parroquia mozárabe de San Marcos una profunda reparación en su armadura, chapitel y paredes maestras, según atestiguó el 21 de octubre de 1709 el maestro de obras y alarife de Toledo (de edad de 41 años, poco más o menos), Francisco González, enviado por don Francisco de Contreras y Castro, catedrático de Vísperas en Cánones de la Universidad de esta ciudad, Teniente de Contador mayor, Juez ordinario de Rentas Decimales en Toledo y todo su arzobispado.

Cuatro años más tarde (4 de diciembre de 1713), en el testimonio que Francisco González dio ante el escribano de Rentas Decimales, Gabriel Ruiz de Arrieta, manifestó que, atendiendo la orden de don Francisco de Contreras y Castro, visitó el 21 de octubre de 1709 la parroquial de San Antolín y San Marcos, de esta ciudad, y reconoció con toda atención los reparos que su iglesia requería, así en su chapitel como en sus armaduras y paredes maestras. A aquellas reparaciones que señaló, ahora había que añadir un aumento del coste debido a los mayores daños que habían sufrido las armaduras y el chapitel en este intervalo de tiempo, debido a las inclemencias de los tiempos.

Su dictamen actual era el siguiente:

\footnotetext{
6 Archivo Histórico Provincial de Toledo (AHPTo), prot. 491, p. 154 y ss.
} 
- Primeramente, se había de desmantelar toda la armadura exterior del chapitel ${ }^{7}$ de la torre de la iglesia, por estar podrida por las aguas y a una de las vigas de las de la cruz, a la que se le había dañado una cabeza, se le habían de poner unas costillas de álamo negro, de tres dedos de grueso, con su cogote ${ }^{8}$ ajustado, y del todo el largo del brazo de la cruz, clavadas con buenos bellotes ${ }^{9}$, a la vez que a dos cuadrales ${ }^{10}$ que había endebles, se les tenía que añadir y unir otros dos cuadrales para darles fuerza.

- Se había de cubrir con ladrillo y yeso todo el entrevigado de soleras ${ }^{11}$ y estribos ${ }^{12}$ hasta enrasar con los estribos.

- Era necesario volver a ejecutar las armaduras sentando soleras nuevas enterizas de tirantes ${ }^{13}$ de Cuenca y las limas de cuartón ${ }^{14}$.

- Había de realizarse el apendolado ${ }^{15}$ de tirantes de Cuenca, cuadrados; labrado todo a azuela; repartiendo las péndolas de diez a diez dedos, dejando solamente una buhardilla, en la que proporcionar bastante hueco para que pudiera salir un hombre por ella y debía de ir a línea del sol de mediodía. Debía ser de monterilla, con su remate de una bola de cobre dorada.

- Se había de empizarrar haciendo las canalillas de plomo y en los vuelos y donde no se pudiera empizarrar, con su tablero dado de verde y todo su chapitel, se había de entablar con tablas de siete, de buen grueso, labradas, $\mathrm{y}$

Pieza piramidal, poligonal o cónica, que remata la parte superior de una torre o cubierta.

8 Pedazo de madera que sale fuera de un muro, o de los cercos de una puerta o ventana.

$9 \quad$ Clavo de unos $20 \mathrm{~cm}$ de largo y 1 de grueso con cabeza parecida a la de la bellot

10 Maderos que atraviesan en sentido perpendicular a la bisectriz del ángulo que forman dos muros o dos vigas (oblicuamente de una carrera a otra en los ángulos entrantes).

11 Pieza de madera que se coloca horizontal en la parte superior de un muro en el mismo sentido de éste, y sobre el cual se apoya la estructura que soportará la techumbre. Por extensión llámase así a toda pieza de construcción puesta en forma horizontal y sobre la cual se asentarán otras piezas verticales.

12 Macizos de obra adheridos exteriormente al muro para contrarrestar el empuje de una bóveda o arco

13 Elemento de construcción que se emplea para evitar la separación entre dos piezas. Pieza de madera o barra de hierro que impide la separación de los maderos paralelos de un tejado.

14 Limas = Maderos que se colocan en el ángulo diedro que forman dos vertientes o faldones de una cubierta, y en los cuales se apoyan los pares cortos de la armadura.

15 Colocar péndolas. Péndola = Cada una de las piezas verticales de la armadura de una cubierta juntadas todas, cuadradas, muy clavadas con chillones ${ }^{16}$.

- También se había de empizarrar todo el chapitel y el pedestal, siendo de plomo lo que no se pudiera hacer de pizarra.

- Las pizarras debían asentarse solapando los dos tercios, así como poner un garabato de hierro fuerte y con buena espiga, clavado, para poder echar un paral ${ }^{17}$ si se ofreciese salir a quitar alguna gotera.

- Era preciso entablar todo el tabladillo que estaba debajo de las campanas, con tablas gruesas clavadas con chillones y meter dos cuartoncillos en el suelo cuadrado.

- Asimismo, se debían hacer a todas las ventanas antepechos de tabique doble con puentes de cuartón ${ }^{18}$ labrados.

- Se habían de rehacer en la escalera todos los antepechos que se hallaban caídos, así como asentar todos los peldaños que faltaban.

- Imprescindible era rematar todo de yeso y dejarlo limpio de broza.

- Otra condición era que se debía de desmontar todo el colgadizo de la nave de Nuestra Señora de Belén y lo que se seguía hasta la entrada de la tribuna y hacer en todo ello un colgadizo de cuartón, cabeceando las paredes pie y medio, repartiendo siete pilares en los tirantes de ladrillos y cal, de tres frentes y medio cada una y enrasarlos de mampostería de barro revocado de cal por dentro y fuera, con una hilada de ladrillo a plomo y dos voladas que volasen cada una cuatro dedos.

- Se habían de asentar nudillos ${ }^{19}$ de cuartón de cuatro a cuatro pies y soleras de cuartón y hacer sus colgadizos entramados de cuartones para franquear las armaduras y descargarlas del mucho peso que tenían.

- Era preciso repartir los cuartones de suerte que quedase un pie de cuartón a cuartón y entablarlo aprovechando la tabla vieja. Lo que faltase se había de poner nuevo, así como reparar las armaduras sentando en ellas doce

16 Clavos especiales de construcción, de hierro, de unos 6 $\mathrm{cm}$. de lago y espiga delgada y piramidal que se emplea generalmente para clavar tablazones delgadas y de ínfima calidad de los techos

17 Madero que se aplica con oblicuidad a una pared, y sirve para asegurar en él el puente de un andamio

18 Cada uno de los maderos que resultan de aserrar longitudinalmente en cruz una pieza enteriza. Viga o pieza de madera que se ubica entre dos armaduras en cubierta, se la coloca inclinada o en enrejado.

19 Cada una de las vigas horizontales que unen los pares de la armadura de par y nudillo 
pares $^{20}$ y las tablas que faltaren correspondientes a lo antiguo y tejar dichos colgadizos a torta y lomo ${ }^{21}$ cerrado, solapando el tercio de la teja haciendo aleros, arzonales ${ }^{22}$ y boquillas de cal.

- Se había de quitar la buhardilla que caía a la capilla de la Virgen por ser muy perjudicial al tejado y tener bastante luz respecto de tenerla tapada y volver a hacer la que caía a la capilla mayor en la misma forma que estaba.

- En cuanto a la pared de la capilla de Nuestra Señora de la Soledad, que hacía división a la sacristía, se había de demoler toda, desde la esquina de la torre hasta la otra esquina, que era toda la cortina de la nave de dicha capilla, desenvolviendo toda la armadura, haciendo todos los apuntalados suficientes para darle seguridad y volver a ejecutar dicha pared desde lo firme, sacando el cimiento de mampostería de cal hasta el piso de la iglesia. Después se habían de erigir cuatro pilares de albañilería de cal, dejando el claro de la puerta de la sacristía en el mismo sitio que al momento se hallaba.

- La alacena que estaba al lado del altar se había de conservar, por el contrario, la otra alacena, que estaba a la parte de la torre, se había de condenar, porque tantos huecos quitaban mucha fuerza a la pared.

- Se erigiría en la esquina que caía al patio de la casa del curato un macho de albañilería de cal, que tuviese cada ramal cinco frentes y medio de menor y seis y medio de mayor y en la esquina que arrimaba al altar se había de levantar otro pilar de tres frentes y medio de menor y cuatro y medio de mayor. Los otros dos machos del medio habían de tener tres frentes y medio de menor y cinco y medio de mayor, con sus cajones de mampostería de cal y dos hiladas de verdugos ${ }^{23}$ en cada altura, de tres a tres pies. Y en esta forma se había de levantar esta pared hasta enrasar con toda su altura, dándole los mismos gruesos que al momento tenía.

- Se precisaba volver a asentar la armadura poniendo nueva la madera que se desgraciase al tiempo del derribo y hacer su contraarmadura y tejarla.

20 Cada uno de los dos maderos que en un cuchillo de una armadura tienen la inclinación del tejado

21 Tejar a torta y lomo = Asentar las tejas sobre mortero, que rellena las cobijas y los canales.

22 Remates o tejadillos en la parte superior de un muro para protegerle de la lluvia o de otras inclemencias meteorológicas.

23 Hilada horizontal, doble o sencilla, de ladrillo, en una fábrica de tierra o mampostería.
- Se había de jaharrar ${ }^{24}$ toda la pared nueva por la parte de la iglesia y sacristía, con yeso moreno y blanco; por el contrario, las oficinas de la casa del curato sólo se habían de rematar de yeso moreno y hacer los solados que se maltratasen por razón del derribo.

- Asimismo se habían de quitar dos canales maestras que tenía la capilla mayor, sacando las aguas a cuerda con un encamonado ${ }^{25}$ de madera, y contra la torre se había de hacer una armadura a dos aguas, de alfarjía ${ }^{26}$, que abarcase toda la línea de la torre, franqueándola con dos cuartones y tejándola como quedaba dicho más arriba.

- Igualmente se habían de trastejar todos los tejados de la iglesia, haciendo boquillas, caballetes, limas y arzonales de cal y enlomar de barro lo que faltaba.

- También se debían reparar todos los descostrados de la iglesia, con yeso moreno y blanco y revocar los cimientos por la parte del patio y el de la sacristía, que está contigua a la torre, se había de realzar de cal metiendo puntos de albañilería donde le cupiere.

- Era condición que la argamasa que se había de gastar en la obra debía de consistir en una mezcla de tres espuertas de arena y dos de cal y el yeso debía ser puro.

- Los materiales del derribo debían ir en aprovechamiento del maestro que hiciese la obra.

- La iglesia debía quedar limpia de broza, tanto por dentro como por fuera.

- Después de un estudio pormenorizado, deducía que el coste de la obra de reparación, incluyendo materiales y mano de obra, ascendía a once mil quinientos reales, poco más o menos.

El escribano firmó el presente documento de traslado de los autos realizados para la reparación de la iglesia mozárabe de san Marcos, de Toledo, dando fe de su autenticidad, el 16 de abril de 1714 .

24 Dar una capa de yeso blanco, estuco u otra mezcla, a las paredes de una casa con objeto de obtener una superficie lisa. Allanar con yeso una pared antes de enlucirla.

25 Encamonar = Hecho con camones, armazones de caña o listones.

26 Tira de madera usada con diversos fines, como tapajuntas, para sostener un elemento o inmovilizarlo, separar dos molduras o superficies, etc. También llamada filete, lata, listel, listón, ristrel, tabla de chilla, tejamanil. Cada uno de los maderos que se cruzan con las vigas para formar la armazón de los techos 
Ajuste de las condiciones de la reparación

El mismo día, es decir, el 16 de abril de 1714 , en que el escribano firma el traslado de los autos para la reparación de la iglesia, se presentaron ante él Manuel Escribano, maestro de carpintería, y Juan Sánchez de Marcos, maestro de albañilería, quienes se obligaron en favor de la Dignidad Arzobispal y señores partícipes interesados en las rentas decimales de la parroquial mozárabe de San Marcos y San Antolín, de Toledo, a que ejecutarian toda la obra de reparación que necesitaba la iglesia y el chapitel de su torre, conforme a la declaración realizada por Francisco González, maestro de obras y alarife de Toledo, en virtud de la comisión ordenada por el Teniente Contador Mayor de Rentas Decimales de 4 de diciembre de $1713^{27}$. Las condiciones a que se someten eran:

- Ejecutarían las obras por 9.900 reales, incluyendo materiales y mano de obra, cantidad que ajustaron con el Teniente Contador Mayor y con Miguel Díaz Barroso y Eugenio de las Infantas, curas de dichas parroquias.

- El cobro de dicha cantidad debía realizarse de la siguiente manera: 5.000 rs. para iniciar los trabajos; 2.600 rs. en septiembre próximo y los 2.300 rs. restantes en septiembre del año siguiente.

- Darían acabadas las obras el 15 de octubre del año en que firmaban las condiciones, es decir, de 1714.

- En caso de que se reconociese por ambas partes que había que realizar alguna actuación arquitectónica que no estuviese comprendida en las condiciones de Francisco González, se les habría que abonar las demasías que hubiesen sido necesarias.

La presente escritura de compromiso fue firmada por los interesados dicho día y fueron testigos Diego Pérez de Betanzos, don Mateo de Contreras, presbitero comisario de la Inquisición y Francisco Aguado, todos ellos vecinos de Toledo.

\section{Destino final de la iglesia}

Por fin, esta iglesia, después de casi doce siglos de existencia, se debió derrumbar en el último tercio del siglo XVIII, según se desprende de los documentos aportados por Julio

27 AHPTo, prot. 491, p. 158 y ss.
Porres Martín-Cleto ${ }^{28}$. En los documentos XXIII a XXV, en 1792 el párroco de San Marcos, solicitaba al cardenal Lorenzana dineros para continuar con el cercado del solar de la iglesia derribada poco antes por ruina y en el no XXVI don José García Balmaseda, cura párroco de la parroquia de San Marcos, de Toledo, pide en abril de $1794 \mathrm{al}$ mismo prelado, que se dignase contribuir a la finalización de las obras de la iglesia de esta parroquia, que al momento albergaba a la de San Antolín, "haviendo V. Em tenido la bondad en el año de 92 mandar que se alzasen las paredes de la Parroquia de $S$. Marcos a una proporcionada altura, y grueso correspondiente, con la portada igual a la que antes tenía, lo que se practicó en el año 93, con bóvedas mui decentes, donde se hallan varios sepulcros, y la pieza que corresponde a Sacristía, concluido". Al parecer la torre, que subsistía en 1841, fue demolida en 1857 tras la compra del edificio por un especulador acogiéndose a la ley desamortizadora de Madoz de 1-5-1855 $5^{29}$. La parroquia se trasladó a la iglesia de El Salvador después de diversos traslados ${ }^{30}$. $\mathrm{Y}$ tras producirse un incendio en 1823 en esta última, aprovechando que en 1821 fuese suprimida la comunidad conventual de trinitarios, se la reubicó en el espacioso templo de los trinitarios calzados. Pero ahí no terminó su periplo, sino que posteriormente se la desplazó a Santa Eulalia, donde reside en la actualidad.

28 PORRES MARTÍN-CLETO, J., Historia de las calles de Toledo, $3^{\mathrm{a}}$ edic. revisada y aumentada, Toledo, 1988, tomo II, p. 594 y tomo III, Fondo documental, documentos $\mathrm{n}^{\circ}$ XXIII a XXVI

29 PARRO, S.R., Toledo en la... t. II, p.186.

30 RAMÍREZ DE ARELLANO, R., Las parroquias de Toledo, Toledo, 1921, reprod. del IPIET, serie V, Clásicos toledanos, $n^{\circ}$ 9, pp. 35, 39, 42 y 43, nos informa que a esta parroquia mozárabe se trasladó la de San Antolín (parroquia latina) cuando el edificio de esta se aplicó al convento de Santa Isabel. Ambas parroquias fueron trasladadas en el último tercio del siglo XVIII a San Bartolomé por ruina del edificio y el 2 de enero de 1790 pasaron a San Cristóbal. De aquí fueron trasladadas a la iglesia de El Salvador en 1798 y, posteriormente, la de San Marcos pasó interinamente a la Trinidad, tras el incendio de El Salvador en 1823. Su periplo terminó en Santa Eulalia, ARELLANO CÓRDOBA, A., "Una parroquia trashumante", Crónica Mozárabe, n 5 , Toledo, 1981, pp. 4-5. Sobre las vicisitudes y traslados de las parroquias de El Salvador y San Antolín, ver también RODRÍGUEZ MOLINA, Ma JOSÉ y ALGUACIL MARTÍN, $M^{a}$ EUGENIA, "El archivo parroquial de Santo Tomé de Toledo. La historia de distintas reorganizaciones parroquiales", en Archivos de la Iglesia de Castilla-La Mancha, Cuenca, 2018, pp. 162-163 


\section{Para evitar confusión}

En Toledo se conoce como iglesia de San Marcos, no la que acabamos de hablar, pues como decíamos, desapareció hace ya muchos años y muy pocos la tienen en su recuerdo y, quizás, ni sepan de su existencia, sino la que fuera inicialmente la iglesia del convento de Trinitarios Calzados (siglo XIII), reedificada de nueva planta en 1628 por hallare en ruinas, y que tuvo como arquitecto y autor del diseño a Jorge Manuel Theotocópuli (1578-1631) (11 $^{\text {, don- }}$ de permaneció la parroquia mozárabe de San Marcos hasta que, como hemos dicho, fue trasladada a la iglesia de Santa Eulalia. Al templo se le realizaron modificaciones en el XVIII.

Según Julio Porres Martín-Cleto ${ }^{32}$, en 1179 ya existía en la calle de la Trinidad, de Toledo, una iglesia parroquial -aseveración basada en un documento presentado por J. F. Rivera Recio en su obra Los Arzobispos de Toledo en la Baja Edad Media, (Toledo, 1969) -, antecesora del convento de la Trinidad. Pedro Alcocer, en su Historia o Descripción de la Imperial Cibdad de Toledo, (Toledo, 1554, Fo.ciii), escribe que en el reinado de Alfonso VIII, un religioso de la orden trinitaria, llamado fray Elías, alcanzó del monarca licencia para fundar un pequeño monasterio, que en principio estuvo ubicado en una casa que compró. El edificio aumentó en 1220 con la cesión de una propiedad por parte de don Fernán Pérez Pantoja, en la que se construyó una iglesia. Este monasterio se acrecentó con nuevas donaciones de ese mismo personaje.

En el primer tercio del siglo XVII realizaron los monjes una reforma total del edificio y decidieron construir una iglesia monumental, de cuyas obras se encargó Jorge Manuel Theotocópuli en 1628. Dicha iglesia no fue terminada hasta 1693 tras cubrir la cúpula sobre el tramo central del crucero; sin embargo, las capillas absidales son de inicios del XVIII.

Como hemos dicho, en 1821 fue suprimida la comunidad de trinitarios, lo que se apro-

\footnotetext{
SUÁREZ QUEVEDO, D., La iglesia de la Santísima Trinidad de Toledo (parroquia de san Marcos) obra de Jorge Manuel Theotocópuli”, Anales Toledanos, n 38, 2001, pp. 61-82 y “Jorge Manuel Theotocópuli, tracista y arquitecto de la iglesia de la Santísima Trinidad de Toledo, versus parroquia de San Marcos", Archivo Español de Arte, LXXI, 284, Octubre-Diciembre 1998,

32 PORRES MARTÍN-CLETO, J., Historia de las calles..., tomo III, p. 1463
}

vechó para instalar en su iglesia la parroquia mozárabe de San Marcos, al producirse un incendio en 1823 en la iglesia de El Salvador, donde se hallaba ubicada dicha parroquia mozárabe. Quedó el resto del edificio conventual abandonado después de ser ocupado durante un tiempo por el ejército como cuartel. En 1935 el estado de ruina de las que fueron dependencias de los trinitarios era total y fueron cedidas al Ayuntamiento toledano, quien demolió sus restos en 1960, quedando solamente en pie la iglesia, aunque en muy malas condiciones. Tras la guerra civil, el templo fue utilizado durante bastante tiempo por este organismo como almacén hasta que en 1985 se proyectó realizar en ella un Centro Cultural y en 1999 el conjunto (iglesia y solar del antiguo convento) fue remodelado y modificado por el arquitecto Ignacio Mendaro Corsini, para ubicar en él el Archivo Municipal de Toledo, manteniendo la iglesia como Centro Cultural para exposiciones y actos culturales de muy diferente tipo.

\section{Unos toques sobre el edificio y su tracista}

Jorge Manuel se inclinó hacia la arquitectura, donde brilló más que en la pintura, en contra de la opinión y deseo de su padre, que consideraba este último arte como el más glorioso y superior a todos los demás. Inició su caminar arquitectónico entre 1604-1605, con la adecuación y reestructuración del edificio del mercado de frutas y verduras de Toledo, ubicado en la Plaza Mayor, conocido como "Mesón de la Fruta", para que sirviera también como corral de comedias y del que realizó las trazas y dirigió las obras. En 1612 se hizo cargo de las obras del Ayuntamiento de esta misma capital, corrigiendo la traza que Juan de Herrera realizara en 1574. Sus cambios pueden comprobarse observando la fachada principal: sobre los dos primeros pisos herrerianos se eleva el tercero y más alto (obra de Jorge Manuel), donde cambia las aberturas con arco herreriano de medio punto por otras adinteladas y reduce la altura del piso. Abarcando los tres balcones centrales sitúa un frontón triangular con el escudo toledano. Dejó las torres, a las que añadió un cuerpo más, achaparradas y cubiertas con un chapitel de pizarra que, a finales del XVII, Ardemans elevaría y coronaría con chapiteles barrocos. También actuó sobre el interior del 
edificio: escalera principal, bóvedas y escaleras de caracol de las torres, hasta 1618.

En ese mismo año de 1612, Jorge Manuel trazaba la portada del Colegio de San Bernardino (Toledo), hoy muy alterada y de la que sólo queda el acceso adintelado entre columnas de orden toscano y sus contrapilastras. Entre dicho año y 1618 siguió actuando en Toledo: en el palacio del marqués de Villena y en el convento e iglesia de las Agustinas de San Torcuato. En el primero remodela el corredor y del segundo hoy sólo se puede contemplar del conjunto -pues se derribaron convento e iglesia en el siglo XIX- la portada adintelada de piedra berroqueña con dos columnas jónico-dóricas con sus contrapilastras y frontón curvo partido. Remata la portada un ático con la hornacina del santo titular entre pilastras toscanas y un frontón triangular.

En 1623 traza los planos y las condiciones de la capilla mayor de la iglesia del monasterio de Santa Clara la Real, de Toledo. Dos años más tarde es nombrado maestro mayor de obras de la Catedral toledana, Como tal, se hace cargo en 1626 de la construcción de la cúpula que corona la Capilla de los Mozárabes, que se realiza según sus trazas y condiciones. Esta cúpula, terminada en 1631, constituye la bella y original asimetría de la fachada del templo.

La construcción de la iglesia del convento de los Trinitarios Calzados, de Toledo, por parte de Jorge Manuel, bajo la advocación de la Santísima Trinidad (título que tomaría la calle donde se halla ubicada), se llevó a cabo a partir de 1628 de nueva planta debido a la ruina en que se encontraba ${ }^{33}$, es decir, no se encontró constreñido ni forzado por planteamientos anteriores. Su actuación se debió a la función que ejercía como maestro mayor de obras de la catedral (cargo que ostentó entre 1625 y 1631, a la vez que era también maestro mayor de los Alcázares Reales de Toledo, y de su Ayunta-

33 RAMÍREZ DE ARELLANO, R., Las parroquias de..., p. 198, escribe que el arquitecto de la iglesia del convento de la Trinidad fue fray José de Segovia y que la obra se terminó en 1628. No comprendemos cómo en ese mismo año necesitara una remodelación debido a hallarse ruinosa. Creemos que este autor debió manejar datos erróneos, aunque no especifica de dónde los tomó. Según Sixto Ramón PARR0, Toledo en la..., tomo II, p. 187, debió tomar la noticia de Amador de los Ríos, Toledo Pintoresca, quien a su vez interpretaría mal las noticias de Ponz al hablar de este fraile y de esta iglesia, ya que sólo su implicación fue la de disponer se hicieran las obras como superior trinitario. miento desde 1621) y a la protección y amparo de fray Hortensio Féliz Paravicino (vicario general de los Trinitarios Calzados en Castilla, León y Navarra), amigo y admirador del arte de su padre.

A principios del siglo XVII era una reflexión $\mathrm{y}$ un convencimiento en Toledo la necesidad de la reparación de la iglesia trinitaria dado el estado ruinoso en que se encontraba, llegándose a la conclusión y acuerdo de 4 de abril de 1628 entre el Ayuntamiento y el entonces padre provincial de la orden fray Hortensio Félix Paravicino de su construcción sobre planta nueva. En realidad, ya con anterioridad se habían iniciado obras en la misma pues con fecha 6 de febrero, el maestro de obras toledano Francisco de Espinosa, había firmado su contrato declarando que la realizaría bajo las órdenes de Jorge Manuel $^{34}$. En 1636 este mismo maestro de obras subscribe un nuevo contrato, en este caso para remates de última hora (jaharrado o blanqueado de bóvedas, cañón y sotocoro ${ }^{35}$.

La iglesia es, junto a la de San Ildefonso (Padres jesuitas), la de mayor tamaño de Toledo (exceptuando la catedral). Tiene forma de cruz latina y consta de tres naves. La central el doble de amplia que las laterales, con cubierta de medio cañón con lunetos. Una serie de grandes pilastras dóricas suben por las paredes hasta la cornisa. Se separa de las naves laterales, más bajas y cubiertas con bóvedas vaídas, con arcos de medio punto. El crucero, que no sobresale en planta, es muy espacioso y se cubre con una grandiosa cúpula en forma de media naranja ${ }^{36}$. El presbiterio es poco profundo, con testero plano y un tanto elevado con respecto al transepto. El coro, en alto, de grandes dimensiones, está situado a los pies del templo. Debido a problemas económicos, la capilla mayor no se inició hasta mediados de la década 1630-1640 y, hasta finales de la de 1670-1680, no se comenzó a construir la cúpula sobre el tramo central del crucero, que quedó terminada en $1693^{37}$.

34 SUÁREZ QUEVEDO, D., “Jorge Manuel Theotocópuli, tracista y arquitecto de la iglesia de la Santísima Trinidad de Toledo, versus parroquia de San Marcos”, Archivo Español de Arte, LXXI, 284, Octubre-Diciembre 1998, p. 408

35 El coro fue diseñado en el 1636 por el maestro de obras Juan García de San Pedro, SUÁREZ QUEVEDO, D., "La iglesia de la Santísima Trinidad..., pp. 64-65

36 Esta cúpula no fue construida hasta 1693, y nada tiene que ver con la tracería de Jorge Manuel

37 LLAGUNO Y AMÍROLA, E., Noticias de los arquitectos y arquitectura de España desde su restauración, Madrid, 1829 (Edic. facsímil de 1977), t. IV p. 28 
Mientras la capilla absidal del lado de la epístola es obra de la segunda mitad del siglo XVII, la del evangelio lo es de inicios del XVIII. Algunas voces atribuyen la fachada de acceso al templo a Juan Bautista Monegro, aunque no presentan documentación al respecto; sin embargo, es posible ya que es una estructura anterior, fuera conservada por Jorge Manuel cuando cambió la disposición del templo para darle un mayor grandeza y esplendor, a petición de los conventuales ${ }^{38}$. Esta fachada está formada por una puerta con arco de medio punto sobre pilastras, flanqueada por dos columnas de estilo dórico sobre pedestales, las cuales soportan un cornisamento. Por encima un segundo cuerpo con tres hornacinas, la central de mayor tamaño que las laterales, actualmente vacías ${ }^{39}$. Corona la fachada una espadaña con tres huecos para las campanas y un ático con una hornacina vacía, toda ella en ladrillo visto y obra del alarife toledano Francisco de Espinosa. Exteriormente, el edificio causa sensación de pesadez, con pocos vanos y perfiles rectilíneos de gran altura. Es ostensible su robusto cimborrio, con cubierta de pizarra.

39 Según el vizconde de Palazuelos en su obra Toledo, guía artístico-práctica, tomo II, Toledo, 1890, (edición facsímil de 1984) p. 699, estas hornacinas cobijaban, la central a un ángel en actitud de proteger a dos cautivos que se hallaban arrodillados ante él y las laterales los santos Juan de Mata y Félix de Valois respectivamente. Atribuye estas estatuas al célebre escultor Pereira. 
